\title{
Duration of fertility of turkeys inseminated at different times after the onset of photostimulation
}

\author{
M. R. Bakst \\ U.S. Department of Agriculture, Agricultural Research Service, Avian Physiology Laboratory, \\ Beltsville, Maryland 20705, U.S.A.
}

\begin{abstract}
Summary. To investigate the relationship between photostimulation, ovary and oviduct weights, and oviducal sperm-storage tubule (SST) development and functional capacity, 33-week-old turkey hens were placed in four groups of 15 hens each. Each group was inseminated three times in $30 \mathrm{~min}$ with $50 \times 10^{6}$ spermatozoa (a total of $150 \times 10^{6}$ spermatozoa) on the day of photostimulation, or on Days 7, 14, or 21 after the onset of photostimulation (Groups A, B, C and D, respectively). From weeks 4 to 8 after photostimulation, 5 additional hens were inseminated each week and then killed $24 \mathrm{~h}$ later to determine ovary and oviduct weights and SST status. Regardless of ovary and oviduct weights and insemination times in relation to photostimulation, 76 of 78 hens possessed morphologically differentiated SST, and 73 of the 76 hens had some SST which contained spermatozoa. For Groups A, B, C and D, the duration of fertility was $\sim 7-8$ weeks. It is concluded that morphologically differentiated SST are functional in 33-week-old hens regardless of the status of the ovary and oviduct.
\end{abstract}

Keywords: turkey; artificial insemination; fertility; semen; hen

\section{Introduction}

Artificial insemination (AI) of the turkey breeder hen before the start of egg production (oviposition) results generally in a high initial rate of fertility (McIntyre et al, 1982). These authors suggested that before the onset of egg production the oviduct, and particularly the sperm-storage tubules (SST) located at the uterovaginal junction, are more receptive to spermatozoa and, therefore, maintain a larger reservoir of spermatozoa within the SST than in hens inseminated after the onset of egg production. It has also been suggested that AI before the onset of egg production allows more time for spermatozoa to reach and enter the SST (McIntyre \& Christensen, 1983). A more precise physiological basis of the observed higher fertility in hens inseminated before the onset of egg production compared to hens initially inseminated after the onset of egg production has not been suggested.

Sperm-storage tubules are present in the oviduct of 30 -week-old hens possessing immature ovaries and oviducts and not yet exposed to stimulatory light (here defined at $14 \mathrm{~h}$ of continuous light followed by $10 \mathrm{~h}$ of no light) (Bakst, 1987). Even though SST are present in such hens, there is no evidence to suggest whether they are capable of storing spermatozoa and maintaining the fertilizing ability of the resident spermatozoa. The present study investigated these matters.

\section{Materials and Methods}

Experiments. Medium White turkey breeder hens were used in fall (September-November, Trial 1) and spring (March-May, Trial 2) trials (60 hens per trial). Initially, poults were maintained in floor pens in a light-proof grow-out facility on $6 \mathrm{~h}$ light $(10: 00-16: 00 \mathrm{~h})$. At 33 weeks of age the hens were moved to a light-proof environment-controlled 
house, caged individually and provided with food and water ad libitum. The regimen of $6 \mathrm{~h}$ light was continued for 2 days and then the light exposure was increased to $14 \mathrm{~h}(03: 00-17: 00 \mathrm{~h})$. Day of photostimulation was considered Day 0.

For each trial, hens were randomly divided into 4 groups of 15 hens and each group was inseminated on a separate day after the onset of photostimulation (Group A, Day 0; Group B, Day 7; Group C, Day 14; Group D, Day 21). Individual hens served as replications for all data variables measured. Artificial insemination (AI) consisted of 3 tandem inseminations (in 7-9-min intervals) of $20 \mu \mathrm{l}$ semen diluted with Beltsville Poultry Semen Extender (Sexton, 1980). Each AI dose contained $50 \times 10^{6}$ spermatozoa for a total of $150 \times 10^{6}$ spermatozoa per hen. If the vagina was occluded by a membranous fold (referred to here as the hymen) when the oviduct was everted, the inseminator gently punctured the hymen, expressed the fluid contents, and proceeded with the insemination. Within each trial, pooled semen from the same males was used on each insemination day.

The day a hen laid the first egg and the day a hen first squatted was determined based on twice daily walk-throughs of the hen facility beginning from Day 0 to the end of the experiment. The day of first squatting was determined based on the first observation of squatting behaviour and the persistence of such behaviour after gentle prodding.

Starting at Day 0 through the 3 rd week after photostimulation, 5 hens per group were killed $24 \mathrm{~h}$ after insemination (except for Group A, Trial 1, from which hens were killed just before AI) with pentobarbitone sodium and the ovaries and oviducts were excised and weighed. An additional 5 hens per week were inseminated as above from Weeks 4 to 7 after photostimulation and then killed as described above to follow ovary and oviduct development and SST sperm-storage capacity further. The location of an oviducal egg-mass was noted and the egg-mass was removed before weighing the oviduct. The presence or absence of SST in unfixed mucosa of the uterovaginal junction was determined (Bakst, 1987). The uterovaginal junction was then divided into 5 equal longitudinal segments and the 2nd and 5th segments were prepared for light microscopy. The presence or absence of spermatozoa in 4- $\mu \mathrm{m}$ thick histological sections of the uterovaginal junction and SST were determined as described by Van Krey et al., (1971). A minimum of one section from two slides per hen was examined. The number of SST cross-sections per section ranged from 60 to 300 , with group totals ranging from 1500 to 2200 SST cross-sections.

Analysis of data. Analysis of variance (ANOVA) of a completely random design was used to determine the effects of treatment (Groups A, B, C and D) and experimental trial (Trials 1 and 2) on the day of first squatting, the day of first laying, and ovary and oviduct weights (included here are hens from Day 0 to Week 7 of photostimulation). Means of significant effects $(P<0.05)$ were separated using a Multiple Least Significant Difference (LSD) technique for unequal sample sizes. Simple linear correlation analysis was used to estimate the degree of association between days of first squatting and laying (SAS, 1985).

Analysis of variance of a completely random design was used to determine the effects of trial and weeks of photostimulation (Day 0 through Week 7 of photostimulation) on the percentage of SST containing spermatozoa. Means of significant effects were separated using Duncan's multiple range test.

The percentage of fertile eggs at candling for each hen (considered a replicate within each group) for each week after photostimulation starting at Week 3 was transformed (arcsin). Analysis of variance of a completely random split-split plot design (within treatment groups and within trials) was used to determine the effects of group treatment and experimental trial on egg production and fertility. An additional source of variation, week after AI, was used to equalize the effects of staggered, weekly inseminations between individual groups. Least square means were calculated to adjust for unequal sample sizes (SAS, 1985). Statistical analyses of percentage data were done on arcsin transformed data, and the means presented in Tables 2 and 3 represent backtransformed least square means.

\section{Results}

\section{Ovary and oviduct weights and presence of SST}

There were no significant trial effects $(P=0.08 ; P=0.28)$ nor trial $\times$ group treatment interactions $(P=0.47 ; P=0.12)$ for ovary and oviduct weights, respectively. The significant source of variation in ovary $(P=0.0001)$ and oviduct $(P=0.001)$ weights was limited to the weeks after the onset of photostimulation (Table 1). There were no trial or group effects of trial $\times$ group interaction with regard to the presence or absence of SST: $97 \%$ of all hens (76/78) examined possessed SST, and $96 \%$ of these hens $(73 / 76)$ had some SST containing spermatozoa.

\section{Hen squatting and egg production}

There were no significant trial $\times$ group treatment interactions $(P=0.94 ; P=0.68)$ or group treatment effects $(P=0.38 ; P=0.39)$ for the means of days of first squat and first lay, respectively. However, for all group treatments trial effects were significant for day of first squat $(P=0.01)$ and day of first lay $(P=0.05)$. The mean values were 6 days and 16 days in Trial 1 and 8 days and 18 
Table 1. Ovary and oviduct weights (across trials), and percentage of sperm-storage tubules (SST) containing spermatozoa (within trials) by week after the onset of photostimulation of turkey hens

\begin{tabular}{|c|c|c|c|c|}
\hline \multirow{2}{*}{$\begin{array}{c}\text { Week of } \\
\text { photostimulation }\end{array}$} & \multicolumn{2}{|c|}{ Weights (g) } & \multicolumn{2}{|c|}{$\begin{array}{l}\% \text { SST containing } \\
\text { spermatozoa }\end{array}$} \\
\hline & Ovary & Oviduct & Trial 1 & Trial 2 \\
\hline 0 & $14 \cdot 8^{c}$ & $28 \cdot 1^{\mathrm{d}}$ & - & $30 \cdot 8^{x y z}$ \\
\hline 1 & $23 \cdot 7^{\mathfrak{c}}$ & $53 \cdot 3^{\mathrm{c}}$ & $48 \cdot 8^{x}$ & $41 \cdot 7^{x y}$ \\
\hline 2 & $110 \cdot 5^{b}$ & $99 \cdot 7^{\mathrm{b}}$ & $* 45 \cdot 7^{x y}$ & $33 \cdot 0^{x y z}$ \\
\hline 3 & $145 \cdot 7^{a}$ & $111 \cdot 1^{\mathrm{ab}}$ & $16 \cdot 8^{z}$ & $23 \cdot 8^{\mathrm{yz}}$ \\
\hline 4 & $144 \cdot 0^{\mathrm{a}}$ & $106 \cdot 7^{b}$ & $15 \cdot 5^{z}$ & $17 \cdot 8^{z}$ \\
\hline 5 & $131 \cdot 5^{a}$ & $114 \cdot 4^{\mathrm{ab}}$ & $33 \cdot 8^{\mathrm{xyz}}$ & $15 \cdot 6^{z}$ \\
\hline 6 & $142 \cdot 3^{a}$ & $120 \cdot 6^{\mathrm{ab}}$ & $* 12 \cdot 0^{z}$ & $41 \cdot 4^{x y}$ \\
\hline 7 & $143 \cdot 3^{a}$ & $125 \cdot 2^{\mathrm{a}}$ & ${ }^{*} 10 \cdot 4^{x}$ & $17 \cdot 0^{z}$ \\
\hline
\end{tabular}

${ }^{a-d}$ Within each column means (averaged across trials) with different letters are significantly different $(P<0.05)$.

${ }^{x-2}$ Within both columns means with different letters are significantly different $(P<0.05)$.

*Spermatozoa were not observed in the SST of one hen in this group.

days in Trial 2, respectively. Simple linear correlation analyses between the values by trial were significant (Trial 1, $r=0.52, P=0.006$; Trial 2, $r=0.62, P=0.0004$ ).

Total egg production was not affected by trial $(P=0 \cdot 11)$, group treatment $(P=0.59)$ or trial $\times$ group treatment interaction $(P=0.73)$. The mean total eggs produced per hen during the first 9 weeks of egg production was 46 .

\section{Fertility}

Regardless of when the hens were inseminated relative to the onset of photostimulation (group treatment) nearly all hens from all groups laid fertile eggs (Table 2). Over both trials two hens were deleted from the study because they failed to lay a single fertile egg (Trial 1, Groups A and D). Using group treatment (A, B, C, D), number of weeks after the onset of photostimulation (WK-PS), and trials as sources of variation, analysis (ANOVA) indicated a significant group treatment $\times$ WK-PS $\times$ trial interaction $(P=0.0009)$ (Table 2). Group treatment effects within the week after photostimulation became significant after Week 3.

Because of the staggered weekly inseminations between group treatments, a second set of analyses was performed using the number of weeks after artificial insemination (WK-AI), in addition to group treatment and trial, as a source of variation. Analyses (ANOVA) indicated significant group treatment $\times$ WK-AI $(P=0.03)$ and trial $\times$ WK-AI $(P=0.04)$ interactions. All group treatments across both trials showed significant declines in fertility between Weeks 5 and 7 after AI (Table 3). Hens in Groups A, B and C in Trial 1 had uniformly high fertility for Weeks 3 and 4 after AI and remained higher than that in Group D hens throughout this 6-week period. Trial 2 showed a different pattern of fertility from that in Trial 1 in that, after Week 3, hens in Group A had consistently lower weekly fertility than did those in the remaining groups.

\section{Discussion}

The presence of SST in 33-week-old hens at the time of photostimulation was confirmed in this study. Furthermore, based on histological observations of spermatozoa within the SST and the subsequent fertility of hens inseminated on Days $0,7,14$ or 21 after photostimulation it is suggested 
Table 2. Percentage fertility after the onset of photostimulation of turkey hens inseminated on Day 0 (Group A), Day 7 (Group B), Day 14 (Group C) or Day 21 (Group D) after the onset of photostimulation

\begin{tabular}{|c|c|c|c|c|c|c|c|c|}
\hline \multirow{3}{*}{$\begin{array}{l}\text { Weeks after } \\
\text { onset of } \\
\text { photo- } \\
\text { stimulation }\end{array}$} & \multicolumn{8}{|c|}{$\%$ Fertility } \\
\hline & \multicolumn{4}{|c|}{ Trial 1} & \multicolumn{4}{|c|}{ Trial 2} \\
\hline & $\underset{\text { A }}{\text { Group }}$ & $\begin{array}{c}\text { Group } \\
\text { B }\end{array}$ & $\underset{C}{\text { Group }}$ & $\begin{array}{c}\text { Group } \\
\text { D }\end{array}$ & $\begin{array}{c}\text { Group } \\
\text { A }\end{array}$ & $\begin{array}{c}\text { Group } \\
\text { B }\end{array}$ & $\begin{array}{c}\text { Group } \\
\text { C }\end{array}$ & $\begin{array}{c}\text { Group } \\
\text { D }\end{array}$ \\
\hline 3 & ${ }^{a} 99 \cdot 7 x$ & ${ }^{a b} 94.4 x$ & ${ }^{2} 95.4 x$ & - & ${ }^{a} 95 \cdot 0 x$ & a9 $95 \cdot 5_{x}$ & b87.5 & - \\
\hline 4 & ${ }^{\mathrm{a}} 100 \cdot 0 \mathrm{x}$ & ${ }^{a} 99 \cdot 7_{x}$ & $99 \cdot 1_{x}$ & ${ }^{a} 67 \cdot 7_{y}$ & b $72.5_{y}$ & a99.8 & b87.0 & ${ }^{b} 62 \cdot 0 y$ \\
\hline 5 & ${ }^{b} 90 \cdot 0_{x y}$ & ab97.4 $4_{x y}$ & a99.5 & ${ }^{\mathrm{a}} 88 \cdot 1_{\mathrm{y}}$ & ${ }^{c} 43 \cdot 8_{z}$ & ${ }^{a} 96 \cdot 1_{x y}$ & ${ }^{2} 99.9_{x}$ & a $85 \cdot 7 y$ \\
\hline 6 & ${ }^{b} 70 \cdot 6 y$ & $b 8 \cdot 2_{x y}$ & $98 \cdot 6 x$ & ${ }^{a} 76.4 y$ & $\mathrm{~d}^{\mathrm{d}} \cdot 8_{\mathrm{y}}$ & a98.1 $1_{x}$ & ab $95 \cdot 3_{x}$ & ${ }^{2} 89 \cdot 6 x$ \\
\hline 7 & $c^{c} 27 \cdot 1_{z}$ & ${ }^{b} 68 \cdot 6_{y}$ & a97.6x & a75.6y & ${ }^{d} 0.0_{y}$ & b77.8 & ${ }^{b} 81.8 x$ & $90 \cdot 1_{x}$ \\
\hline 8 & ${ }^{\mathrm{d}} 0 \cdot 3_{\mathrm{y}}$ & ${ }^{c} 4 \cdot 5_{y}$ & b79-3x & ${ }^{a} 64 \cdot 4 x$ & ${ }^{\mathrm{d}} 0 \cdot 0_{\mathrm{z}}$ & ${ }^{c} 8.5 y$ & $c^{c} 45 \cdot 3 x$ & ${ }^{a b} 80 \cdot 6_{x}$ \\
\hline 9 & ${ }^{d} 0 \cdot 0, y_{y}$ & ${ }^{c} 0 \cdot 0_{y}$ & ${ }^{c} 21 \cdot 0_{x}$ & ${ }^{b} 29 \cdot 9 x$ & ${ }^{d} 0 \cdot 0_{y}$ & ${ }^{c d} 1 \cdot 0_{y}$ & ${ }^{d} 2 \cdot 4 y$ & ${ }^{b} 52 \cdot 5_{x}$ \\
\hline 10 & ${ }^{d} 0 \cdot 0 x$ & ${ }^{c} 0 \cdot 0_{x}$ & ${ }^{d} 1 \cdot 0_{x}$ & ${ }^{c} 4 \cdot 1_{x}$ & ${ }^{d} 0 \cdot 0$ & ${ }^{\mathrm{d}} 0.0_{\mathrm{x}}$ & ${ }^{\mathrm{d}} 0.0 \mathrm{x}$ & ${ }^{c} 5 \cdot 7_{x}$ \\
\hline 11 & - & - & ${ }^{d} 0 \cdot 0_{x}$ & ${ }^{c} 0 \cdot 0_{x}$ & - & - & ${ }^{\mathrm{d}} 0 \cdot 0_{\mathrm{x}}$ & ${ }^{\mathrm{c}} 0 \cdot 0_{\mathrm{x}}$ \\
\hline
\end{tabular}

Within each trial means with different column superscripts $(a-d)$ or row subscripts $(x-z)$ are significantly different $(P<0.05)$.

Table 3. Percentage fertility by week after individual group artificial insemination (AI) of turkey hens on Day 0 (Group A), Day 7 (Group B), Day 14 (Group C) or Day 21 (Group D) after the onset of photostimulation

\begin{tabular}{|c|c|c|c|c|c|c|c|c|}
\hline \multirow[b]{3}{*}{$\begin{array}{l}\text { Weeks } \\
\text { after AI }\end{array}$} & \multicolumn{8}{|c|}{$\%$ Fertility } \\
\hline & \multicolumn{4}{|c|}{ Trial 1} & \multicolumn{4}{|c|}{ Trial 2} \\
\hline & $\begin{array}{c}\text { Group } \\
\text { A }\end{array}$ & $\underset{\text { B }}{\text { Group }}$ & $\underset{\mathrm{C}}{\text { Group }}$ & $\begin{array}{c}\text { Group } \\
\text { D }\end{array}$ & $\begin{array}{c}\text { Group } \\
\text { A }\end{array}$ & $\begin{array}{c}\text { Group } \\
\text { B }\end{array}$ & $\begin{array}{l}\text { Group } \\
\text { C }\end{array}$ & $\begin{array}{c}\text { Group } \\
\text { D }\end{array}$ \\
\hline 3 & ${ }^{a} 99 \cdot 7_{x}$ & a99.7x & a99.5 & ${ }^{a} 76.4 y$ & a95.0 & ${ }^{a} 98 \cdot 8 x$ & ${ }^{a} 99 \cdot 9_{x}$ & ${ }^{2} 89 \cdot 6 x$ \\
\hline 4 & ${ }^{\mathrm{a}} 100 \cdot 0_{\mathrm{x}}$ & ab97.4x & $98 \cdot 6 x$ & a $75 \cdot 6 y$ & ${ }^{b} 72 \cdot 5 y$ & ${ }^{a b} 96 \cdot 1_{x}$ & ab $95 \cdot 3 x$ & ${ }^{a} 90 \cdot 1_{x y}$ \\
\hline 5 & $90.0_{x y}$ & ${ }^{b} 88 \cdot 2_{x y}$ & a97.6 & ${ }^{2} 66 \cdot 4 y$ & c $43.8_{y}$ & ${ }^{\mathrm{a}} 98 \cdot 1_{\mathrm{x}}$ & b $81 \cdot 8 x$ & ${ }^{a} 80 \cdot 6_{x}$ \\
\hline 6 & ${ }^{6} 70 \cdot 6_{x}$ & b $68 \cdot 6 x$ & b $79 \cdot 3 x$ & b $29 \cdot 9 y$ & ${ }^{d} 2 \cdot 8 z$ & ${ }^{b} 77 \cdot 8 x$ & ${ }^{c} 45 \cdot 3 y$ & ${ }^{b} 52 \cdot 5_{x y}$ \\
\hline 7 & ${ }^{c} 27 \cdot 1_{x}$ & ${ }^{c} 4 \cdot 5_{y}$ & $21 \cdot 0_{x y}$ & ${ }^{c} 4 \cdot 1_{y}$ & ${ }^{\mathrm{d}} 0 \cdot 0_{\mathrm{x}}$ & $8 \cdot 5 x$ & ${ }^{d} 2 \cdot 4 x$ & $5 \cdot 7 x$ \\
\hline 8 & ${ }^{d} 0 \cdot 3_{x}$ & $0.0 x$ & ${ }^{d} 1 \cdot 0 x$ & ${ }^{c} 0.0$ & $0 \cdot 0$ & ${ }^{c} 1 \cdot 0$, & ${ }^{d} 0 \cdot 0 x$ & ${ }^{\circ} 0 \cdot 0_{\mathrm{x}}$ \\
\hline
\end{tabular}

Within each trial means with different superscripts $(a-d)$ or row subscripts $(x-z)$ are significantly different $(P<0.05)$.

that morphologically differentiated SST are functional, i.e. capable of storing spermatozoa and sustaining their viability. The presence of SST in immature oviducts weighing about $28 \mathrm{~g}$ suggests that SST differentiation is in some degree independent of the hormonal interactions which regulate the growth and differentiation of the surface epithelial cells of the oviduct and the subepithelial tubular glands responsible for the synthesis of the egg-white proteins (Schimke et al., 1977). Although Pescatore \& Marquez (1977) noted the proliferation of SST in 1-, 6- and 8-week-old poults given oestradiol alone or in combination with progesterone, Sharp (1980) deduced that, in the chicken hen, the rapidly growing yellow-yolk follicles found during the final maturation of the 
ovary (just before the onset of egg production) are the sources of increasing concentrations of plasma oestrogens and that the plasma progesterone value increases when the largest ovarian follicle is fully developed. Since SST have been observed in hens as young as 18 weeks of age (personal observation) and are clearly functional before ovarian follicle maturation, one must assume that factors other than oestrogen and progesterone affect SST differentiation or that 'baseline' levels of one or both of these steroids act with some other factor in the differentiation of the SST.

Regardless of what the direct effectors of SST differentiation may be, the rapid growth of the oviduct after the onset of photostimulation should lead to a net increase in the number of SST. Since SST were not quantified it is not known if the nearly 4-fold increase in oviduct weight after only 2 weeks of photostimulation is accompanied by a similar increase in the number of SST. Goodrich-Smith \& Marquez (1978) did note that photostimulated hens at 28-31 weeks of age possessed $20 \mathrm{SST} / \mathrm{mm}^{2}$ while hens at $38-56.5$ weeks of age had $25 \mathrm{SST} / \mathrm{mm}^{2}$ (statistical analysis was not provided). If there was a net increase in the number of SST corresponding to the increase in oviduct weight, one would assume that more spermatozoa could be retained in the heavier oviducts which should result in higher fertility levels and longer duration of fertility. The short duration of fertility of hens inseminated the day of the onset of photostimulation (Group A) in Trial 2 when compared to the remaining groups may have been due to fewer SST. However, the corresponding group in Trial 1 had sustained high fertility which would indicate that the absolute numbers of SST may not influence fertility. Two factors which probably played more significant roles in the differences in fertility between Trials 1 and 2 for Group A are differences in season and different inseminators for each trial (the more experienced inseminator worked in Trial 1). Inseminator experience could be a significant factor because the hymen was intact in nearly all Group A hens and had to be punctured before AI. Upon puncture of the hymen, which generally had an opaque blister-like appearance, about $1 \mathrm{ml}$ of a highly viscous fluid was extruded. The initial insemination was made immediately after this fluid was voided. Whether the differences in the days of first squat and first lay between the trials are related to subsequent fertility is not known.

McIntyre \& Christensen (1983) observed that the percentage of SST possessing spermatozoa in turkey hens inseminated before the onset of egg production $(72 \%)$ was significantly greater than in hens inseminated after the onset of egg production (44\%). They suggested that ovulation and/or oviposition and/or the presence of an egg mass in the oviduct may interfere with the process of sperm acceptance into the SST. In the present study, hens inseminated 7 and 14 days (Trial 1) and 7 days (Trial 2) after the onset of photostimulation possessed a higher percentage of SST with spermatozoa (a maximum value of $49 \%$ ) than did hens inseminated at other times. Why the percentages of SST containing spermatozoa in the present study are low relative to McIntyre \& Christensen's (1983) observations is not clear but could be due to differences in management or experimental procedures (e.g. $8 \mu \mathrm{m}$ thick sections examined by McIntyre \& Christensen, 1983).

Observations from the present study and those by Fujii \& Tamura (1963) and Hatch (1983) provide insight into the relationship between sperm storage and the ovulatory status of birds. Oviducal sperm storage before maturation of the ovary (and one assumes before maturation of the oviduct) has been reported for the northern fulmar (Fulmarus glacialis). Hatch (1983) observed that once northern fulmars established a pair-bond and a nest-site, mates would copulate several times over several days and then separate for about 3 weeks on a "pre-laying exodus". Within $24 \mathrm{~h}$ of returning to the nest the female would lay a single egg. Hatch (1983) concluded that since mating activity was unlikely during the pre-laying exodus, then the oviducal SST must function "... as an important pre-adaption that makes the pre-laying exodus possible ...". Hatch (1983) did not find evidence of sperm storage elsewhere in the oviduct. In one of the first studies describing the function of the SST in the chicken, Fujii \& Tamura (1963) noted the presence of spermatozoa in the SST after inseminating hens which were in moult, out of egg production, and possessed an 'inactive' oviduct. Likewise, T. R. Birkhead (personal communication) examined a wood pigeon (Columba palumbus) in the early part of its breeding season: the bird possessed a very small ovary (a maximum follicle diameter of $3 \mathrm{~mm}$ ) and an undeveloped oviduct, but histological examination 
showed abundant SST, many of which contained spermatozoa, in the oviduct. All these observations indicate that SST differentiation and the ability of SST to store spermatozoa precede ovarian follicular maturation and cyto-differentiation of the remaining oviducal segments.

Considering the aforementioned observations as well as the conclusions of Burke \& Ogasawara (1969), which indicated that the release of spermatozoa from the SST in chickens in egg production is not cyclical, i.e. not associated with ovulation and/or oviposition or ". . . a precisely timed neural or hormonal event related to the ovulatory cycle ...", the following hypothesis is proposed. The mechanism which assures that spermatozoa are released from the SST and transported to the site of fertilization is activated just before the first ovulation and is maintained as long as the female is in egg production. Sperm release from the SST is slow and continuous throughout the daily ovulatory cycle (Burke \& Ogasawara, 1969; Bakst, 1981) and, for reasons explained elsewhere (Bakst, 1981), sperm release in the turkey does not cease between clutches. However, based on the work of Bushman et al. (1985), sperm release may cease when the hen is anovulatory, i.e. out of egg production.

An alternative hypothesis is that sperm release from the SST is continuous and is under no external control. Spermatozoa released from the SST between AI and the first ovulation may ascend the oviduct to the secondary sperm storage sites of the infundibulum-magnum junction. However, preliminary attempts at flushing and recovering spermatozoa from these sites in hens inseminated before the onset of egg production were unsuccessful (unpublished). It is possible that the sperm-transport mechanism anterior to the uterovaginal junction becomes functional shortly before the initial ovulation, and so spermatozoa could continuously leave and re-enter SST until the adovarian transport mechanism is functional.

To conclude, the observations in this study offer some practical application to managers scheduling the initial inseminations of a turkey breeder flock. Typically, the first insemination is shortly before or after the onset of egg production, about 15-20 days after the onset of photostimulation. This study shows that insemination is effective and, if necessary, the hymen can be manually ruptured at any time after the onset of photostimulation without affecting the day of first lay, or subsequent egg production and fertility.

I thank Anne Kimrey and Joan Tishue for their assistance and Tom Harris (Statistical Counsulting and Analysis Team, USDA, Agricultural Research Service, Beltsville) for performing the statistical analyses.

\section{References}

Bakst, M.R. (1981) Sperm recovery from oviducts of turkeys at known intervals after insemination and oviposition. J. Reprod. Fert. 62, 159-164.

Bakst, M.R. (1987) Anatomical basis of sperm-storage in the avian oviduct. Scanning Microsc. 1, 1257-1266.

Burke, W.H. \& Ogasawara, F.X. (1969) Presence of spermatozoa in uterovaginal folds of the hen at various stages of the ovulatory cycle. Poultry Sci, 48, $408-413$.

Bushman A.F., Van Krey, H.P., Denbow, D.M. \& Siegel, P.B. (1985) Effect of the ovulatory cycle on oviductal sperm storage in the domestic fowl. Theriogenology 23, 474-479.

Fujii, S. \& Tamura, T. (1963) Location of sperm in the oviduct of the domestic fowl with special reference to storage of sperms in the vaginal gland. J. Fac. Fish. Anim. Husb. 5, 145-163.

Goodrich-Smith, M. \& Marquez, B.J. (1978) Estimation of the numbers of sperm storage tubules located at the uterovaginal junction in turkey oviducts. Poultry Sci. 57, I139.
Hatch, S. (1983) Mechanism and ecological significance of sperm storage in the Northern Fulmar with reference to its occurrence in other birds. The $A u k 100,593-600$.

McIntyre, D.R. \& Christensen, V.L. (1983) Filling rates of the uterovaginal sperm storage glands in the turkey Poultry Sci. 62, 1652-1656.

McIntyre, D.R., Quarles, C.L., Fagerberg, D.J. \& Krueger, K.K. (1982) Fertility of the turkey hen as affected by initial insemination and onset of egg production. Poultry Sci. 61, 1734-1737.

Pescatore, A.J. \& Marquez, B.J. (1977) Sperm storage tubule development in immature turkeys injected with female sex steroids. Poultry Sci. 56, 1746-1747.

SAS (1985) SAS Users's Guide: Statistics, Version 5 Edition. SAS Institute, Cary.

Schimke, R.T., Pennequin, P., Robins, D. \& McKnight, G.S. (1977) Hormonal regulation of egg-white protein synthesis in chick oviduct. In First European Symposium on Hormones and Cell Regulation, pp. 209-221. Eds J. Dumont \& J. Nunez. Elsevier/ North-Holland Biomedical Press, New York. 
Sexton, T.J. (1980) A new poultry extender. 5. Relationship of diluent components to cytotoxic effects of dimethylsulfoxide on turkey spermatozoa. Poultry Sci. 59, 1142-1144.

Sharp, P.J. (1980) Female reproduction. In Avian Endocrinology, pp. 435-454. Eds A. Epple \& M. H. Stetson. Academic Press, New York.
Van Krey, H.P., Siegel, P.N. \& Leighton, A.T., Jr (1971) Repeatability estimates and quantification of uterovaginal sperm-host gland numbers and population patterns. Biol. Reprod. 4, 31-34.

Received 29 February 1988 